\title{
Numerical investigation of bubble dynamics and heat transfer in subcooling pool boiling under low gravity
}

\author{
Tian-Hao Yi ${ }^{\text {a }}$, Zuo-Sheng Lei ${ }^{\mathrm{a}, *}$, Jian-Fu Zhao ${ }^{\mathrm{b}, \mathrm{c}, *}$ \\ a State Key Laboratory of Advanced Special Steel, Shanghai Key Laboratory of Advanced Ferro-metallurgy, School of Materials Science and Engineering, Shanghai University, \\ Shanghai 200072, China \\ ${ }^{\mathrm{b}}$ CAS Key Laboratory of Microgravity, Institute of Mechanics, Chinese Academy of Sciences, Beijing 100190, China \\ ${ }^{\mathrm{c}}$ School of Engineering Science, University of Chinese Academy of Sciences, Beijing 100049, China
}

\section{A R T I C L E I N F O}

\section{Article history:}

Received 16 July 2018

Received in revised form 5 November 2018

Accepted 14 December 2018

\section{Keywords:}

Bubble dynamics

Subcooling boiling

Critical subcooling

Heat transfer

Low gravity

\begin{abstract}
A B S T R A C T
The numerical simulation of a single vapor bubble growth in subcooling liquid under different gravity conditions has been carried out. In the numerical model, a thin superheated layer and the thermocapillary convection caused by the surface tension variation along the surface are considered. The continuity equation and energy equation are modified to allow for the phase change. In addition, the thermocapillary convection effect has been included in the momentum equation. The vapor-liquid interface is captured by the phase field method. The results show that the bubble behavior in the numerical model agrees well with previous experiments conducted in high subcooling liquid under microgravity. The effects of gravity level, contact angle and wall superheat on the bubble growth, critical subcooling (the liquid subcooling under the condition that the evaporation rate of a bubble is equal to its condensation rate), together with heat transfer have been investigated. The growth period and departure radius both reduce with the increase in gravity level, while the critical subcooling increases slightly. Large contact angle at the three-phase contact line augments the departure radius. However, the critical subcooling decreases as contact angle increases. With the wall superheat increasing, the growth period reduces rapidly, while the departure radius and the critical subcooling increase. What's more, the nondeparting bubble adhering to the surface would prevent heat transfer with a dry spot, which may damage the heating element in application.
\end{abstract}

(c) 2018 Elsevier Ltd. All rights reserved.

\section{Introduction}

Boiling is a liquid-vapor phase change process involved with bubble formation, growth and departure, which is one of the most efficient means to achieve high heat fluxes at a moderate wall superheat. Therefore, it is extensively applied in areas of electronics cooling, mechanical engineering, energy and power engineering. Although a great number researches of nucleate boiling have been conducted in the past decades [1-9], the mechanism of boiling heat transfer is still unclear. In terrestrial boiling, buoyancy caused by the gravity and large differences between liquid and vapor densities is often considered as the governing mechanism

\footnotetext{
* Corresponding authors at: State Key Laboratory of Advanced Special Steel, Shanghai Key Laboratory of Advanced Ferro-metallurgy, School of Materials Science and Engineering, Shanghai University, Shanghai 200072, China. (Z. -S Lei) and CAS Key Laboratory of Microgravity, Institute of Mechanics, Chinese Academy of Sciences, Beijing 100190, China (J.-F. Zhao).

E-mail addresses: lei_zsh@staff.shu.edu.cn (Z.-S. Lei), jfzhao@imech.ac.cn (J.-F. Zhao).
}

for bubble dynamics and boiling heat transfer. Comparing to the buoyancy, the inertia force and the surface tension are smaller, which are ignored. Thus, advancement in the understanding of the basic boiling phenomenon have been greatly hindered by the normal gravity. However, microgravity environments weaken the influence of gravity on the bubble, and make it possible to study the self-dynamics of boiling. The investigation of subcooling pool boiling under low gravity can provide fundamental information about bubble behavior and heat transfer. In addition, a comprehensive understanding of nucleate boiling and critical heat flux under low gravity could help figure out the heat removal mechanism covered by the buoyancy in earth gravity.

Up to now, the studies of pool boiling under low gravity have been studied more than fifty years. Different facilities, such as drop tower [10], reduced gravity airplane [11,12], space shuttle [13], satellite [14], and space station [15,16], with the microgravity period from a few seconds to hours have been utilized.

Significant progresses have been made in nucleate pool boiling under microgravity. Qiu et al. [12] studied the effect of low gravity 


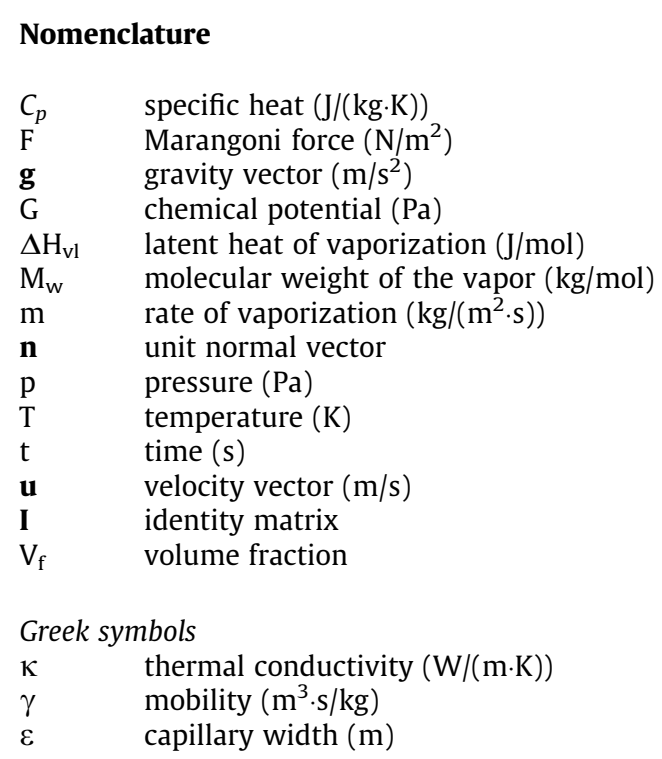

$\lambda \quad$ mixing energy density $(\mathrm{N})$

$\sigma \quad$ surface tension coefficient $(\mathrm{N} / \mathrm{m})$

$\theta \quad$ contact angle $\left(^{\circ}\right)$

$\phi \quad$ phase field variable

$\delta \quad$ smoothed representation of the interface $(1 / \mathrm{m})$

$\Psi \quad$ phase field auxiliary function

$\eta \quad$ dynamic viscosity (Pa.s)

\begin{tabular}{ll}
\multicolumn{2}{l}{ Subscripts } \\
$\mathrm{l}$ & liquid \\
$\mathrm{v}$ & vapor \\
$\mathrm{r}$ & r direction \\
$\mathrm{z}$ & $\mathrm{z}$ direction \\
$\mathrm{e}$ & earth normal gravity \\
$\mathrm{w}$ & wall superheat temperature \\
sat & saturation temperature \\
sub & subcooling temperature \\
int & interface
\end{tabular}

and liquid subcooling on the dynamics of the single bubble with an artificial cylindrical cavity $10 \mathrm{um}$ in diameter etched in the center of a silicon wafer. Compared to those at Earth normal gravity, larger bubble diameters and longer bubble growth period were measured in microgravity. Liquid subcooling had a negligible influence on the bubble departure diameter, but strongly prolonged bubble growth periods. Bubble behaviors were analyzed exhaustively. However, heat transfer characteristics related to bubble dynamics were not considered in the low gravity. Zhao et al. [14] have conducted quasi-steady pool boiling of FC-72 on a plane plate heater in microgravity aboard the Chinese recoverable satellite SJ-8. At high subcooling, the coalesced bubble had a smooth surface and a small size. No turning point occurred when it transited from nucleate boiling to film boiling. However, an obvious turning point appeared in the boiling curve at low subcooling. Heat transfer coefficient and Critical Heat Flux (CHF) were found to increase with the subcooling in microgravity, but the value of CHF was lower in microgravity than that in normal gravity. Although the degassed FC-72 was used as the working liquid, the final dissolved gas concentration in the liquid was not measured, which might affect the measured data. In 2011, Raj et al. [15] and Dhir et al. [16,17] carried out a series of boiling experiments in the Boiling Experimental Facility located in the Microgravity Science Glovebox of the International Space Station respectively. Raj et al. [15] found that the microgravity heat transfer predictions based on the modified scaling law agreed well with the experimental data. Dhir et al. [16,17] found that a lateral merged bubble continued to grow on the heater surface at low wall superheat, whereas the merged bubble may lift off from the heater and hover near the surface at high wall superheat. However, the microgravity experiments mentioned above would cost much and take longer time to prepare in the early stage. With the development of computer performance, the numerical simulation with the advantages of convenience and less cost is applied to investigate bubble dynamics and heat transfer in nucleate boiling.

In 1989, Lee and Nydahl [18] built a model to simulate the bubble growth on a horizontal surface with the microlayer. The momentum and energy equations were solved to obtain corresponding flow and temperature field. But a hemispherical bubble in shape is assumed during its growth, which couldn't indicate the change of the bubble shape during growth period. Stephan and Hammer [19] proposed a model to calculate heat transfer coefficient in nucleate boiling taking into account the influence of meniscus curvature, adhesion forces and interfacial thermal resistance on the thermodynamic equilibrium at the gas-liquid interface. The domain of interest was separated into micro- and macro-regions. The lubrication theory is used to model the laminar flow in the micro-region, which results in a 4th-order non-linear differential equation for the film thickness. The model is later called as the contact line model. Welch [20] studied bubble growth with the Volume of Fraction Method, which is used to track the two-phase interface with phase function. However, the method wasn't extended to the conditions that violent interface change occurred when the bubble departed. Furthermore, the microlayer growth and contact line physics are not taken into account. Son et al. [21] performed a complete numerical simulation of bubble growth and departure, based on a similar contact line model like Stephan and Hammer [19]. The vapor-liquid interface in the macro-region was captured by the level set method which was modified to include the influence of phase change at the liquid-vapor interface. The results showed that the departing bubble became larger with the increase in contact angle and wall superheat, which compared well with that observed in the experiments. Zhao and his colleagues [22-24] also performed a series of numerical simulations on single bubble pool boiling at saturated condition, taking into account of the influences of gravity, thermal capacity of the heated solid wall, contact angle, and so on. Singh and Dhir [25] modified Son et al.'s original formulation to include liquid subcooling effects. They found that the bubble growth rate slowed down and growth period increased with the increase in liquid subcooling, while the departure diameter decreased. Although surface tension was regarded as a function of temperature in the model, thermocapillary convection caused by the surface tension variation along the surface has not been taken into consideration in fact.

Considering that noncondensable gases dissolved in the liquid may be injected into the bubble along with vapor, $\mathrm{Wu}$ and Dhir [26] employed the level set function with the moving mesh method to investigate subcooling boiling in the presence of noncondensables. In this method, the total number of grid points was fixed, but the grid automatically moved and sustained a highly dense node concentration around the interface as the bubble grows in order to compute accurately. The air was taken as the noncondensable gas. They analyzed the influence of noncondensable gas on growth rate, heat transfer and flow field under microgravity. The results showed that the bubble with the presence of air had a large size. As the gravity level decreased, the trend became more substantial. Due to surface tension gradient caused by the gas, 
warmer liquid from the bubble base moved upward and accumulated on the top of the bubble, leading to the formation of a plume. However, no plume formed in the absence of gas. According to the numerical results, noncondensables had a slight effect on the overall rate of heat transfer from the wall to liquid. Actually, the initial vapor bubble grew within the superheated region on the surface, and it got condensed outside the superheated region. In spite of thermocapillary convection included in the model, a superheated layer was not taken into account.

Recently, Pan et al. [27] investigated the single bubble condensation behavior of subcooling boiling flow in two different vertical channels using Volume Of Fluid (VOF) multiphase flow model with the user-defined function (UDF) based on the FLUENT CFD platform. Starting from a circular bubble in a subcooling liquid, the bubble lifetime, size, deformation and flow field characteristics were obtained and analyzed. The simulation results revealed that with the subcooling increasing, the bubble lifetime reduced significantly, and the bubble deformation would be sharper. Especially when the subcooling and the initial diameter reached a certain value, the bubble would break up into small bubbles. However, the external heat flux was not exerted in the model. Only flow field and deformation were described.

The preceding works are significant to understand the boiling process. However, most of them focus on the bubble dynamics and flow field without considering heat transfer. Besides, the superheated layer and the thermocapillary convection caused by the surface tension variation along the surface have not been taken into account in the numerical model. As a consequence, it's unclear to understand the process of bubble dynamics and heat transfer in different subcooling liquid. In this article, a mathematical model of a single bubble based on Navier-Stokes equation and heat conduction equation has been conducted to investigate the nucleate boiling in different subcooling liquid, especially in the critical subcooling when the bubble adheres to the surface with a constant size. A thin superheated layer and the thermocapillary convection caused by the surface tension variation along the surface are included. The effects of gravity level, contact angle and wall superheat on the bubble growth, critical subcooling, together with heat transfer have been investigated.

\section{Numerical model}

\subsection{Model description}

A two-dimensional axisymmetric model of the single bubble is performed with the Laminar Two-Phase Flow model and the Phase Field model. The computational domain in a rectangular coordinate system is shown in Fig. 1, which is $20 \times 40 \mathrm{~mm}^{2}$ in size. At the beginning, a quarter-circle bubble with the initial radius of $1 \mathrm{~mm}$ is set on the surface of the bottom wall which provides heat flux continuously. It is known that the Rayleigh equation [28] regarded a spherical bubble growth in the homogeneous superheated liquid. Therefore, a superheated layer is set on the wall, whose superheat is set about $1 \mathrm{~K}$. Utaka et al. [29] have obtained the thickness of the superheat layer by calculation, which agreed well with that measured by Yamagata et al. [30]. Considering that the thickness of the superheated layer was measured in earth normal gravity and the thickness of the superheat layer under microgravity is still unknown, the initial thickness of the superheated layer is set to $1.5 \mathrm{~mm}$ hypothetically. The phase field method which is based on the fluid free energy model adopts the CahnHilliard equation [31] to distinguish the free interface and phases with phase field variables. $\phi$ is the dimensionless phase field variable such that $-1 \leq \phi \leq 1$. The values in the vapor, liquid and the liquid-vapor interface are defined as $-1,1$ and 0 respectively. In

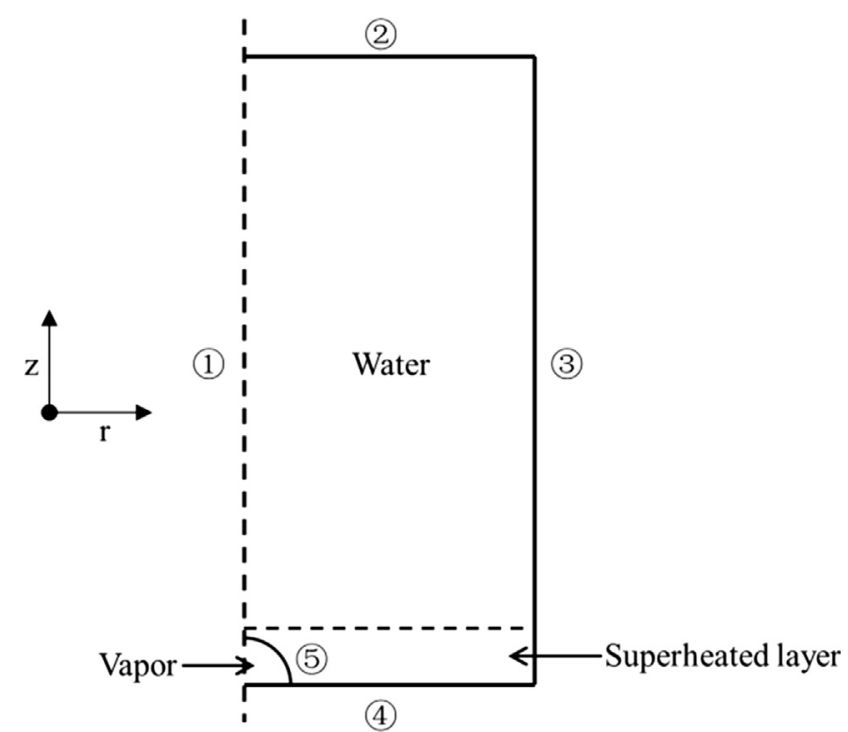

Fig. 1. Typical computational domain.

the model, microlayer evaporation between the bubble and the heated wall is left out although it might have an impact on the heat transfer. The model is a rough approximation, but it could be applied to certain cases where nucleation starts from a fixed cavity of a given size [32].

\subsection{Assumptions}

The following assumptions are made in the study:

(1) The liquid is Newtonian, viscous and incompressible, and the gas is incompressible;

(2) The physical properties of fluids are constant and independent of the temperature except for the surface tension;

(3) The surface tension depends linearly upon the temperature;

(4) The flows are laminar.

\subsection{Governing equations}

The momentum equation includes the surface tension effect and the thermocapillary convection effect:

$\rho \frac{\partial \mathbf{u}}{\partial t}+\rho(\mathbf{u} \cdot \nabla) \mathbf{u}=\nabla \cdot\left[-p \mathbf{I}+\eta\left(\nabla \mathbf{u}+(\nabla \mathbf{u})^{T}\right)\right]+\rho g+G \nabla \phi+F$

Here $G$ is the chemical potential (Pa), which is represented by the equation:

$G=\lambda\left[-\nabla^{2} \phi+\frac{\phi\left(\phi^{2}-1\right)}{\varepsilon^{2}}\right]$

$\lambda$ is the mixing energy density $(\mathrm{N}) . \varepsilon$ is a capillary width that scales with the thickness of the interface $(\mathrm{m})$, which is set about $1.2 \times 10^{-4} \mathrm{~m}$. These two parameters are related to the surface tension coefficient via

$\sigma=\frac{2 \sqrt{2}}{3} \frac{\lambda}{\varepsilon}$

The continuity equation is modified to account for the phase change from liquid to vapor during evaporation (or the phase change from vapor to liquid during condensation):

$\nabla \cdot \mathbf{u}=m \delta\left(\frac{1}{\rho_{v}}-\frac{1}{\rho_{l}}\right)$ 
The energy equation includes phase change:

$\rho C_{p} \frac{\partial T}{\partial t}+\rho C_{p}(\mathbf{u} \cdot \nabla) T=-\nabla \cdot \kappa \nabla T-\frac{m \delta \Delta H_{v l}}{M_{w}}$

Here $M_{w}$ is the molecular weight of the vapor $(\mathrm{kg} / \mathrm{mol})$ and $\Delta H_{v l}$ is the enthalpy of vaporization $(\mathrm{J} / \mathrm{mol})$.The mass flux leaves from the liquid into the vapor (or from the vapor into the liquid):

$m=-\left(\frac{M_{w}}{\Delta H_{v l}}\right) \mathbf{n} \cdot \kappa_{v} \nabla T_{v} \approx C \rho_{l} \frac{\left(T-T_{\text {sat }}\right)}{T_{\text {sat }}}$

Here $C$ is constant $(\mathrm{m} / \mathrm{s})$, which is large enough that the temperature at the interface remains at the saturation temperature but not so large that numerical instabilities result. The interface velocity due to evaporation (or condensation):

$\mathbf{u}_{\text {int }}=\mathbf{u}_{l}-\frac{m}{\rho_{l}} \mathbf{n}$

$\delta$ is a smoothed representation of the interface between the two phases.

$\delta=6 V_{f}\left(1-V_{f}\right) \frac{|\nabla \phi|}{2}$

In the phase field interface, the volume fractions of the individual fluids are:

$V_{f, l}=\frac{1+\phi}{2}$

$V_{f, v}=\frac{1-\phi}{2}$

$F$ represents the Marangoni force caused by surface tension variation in the Navier-Stokes equation, which can be described by as:

$F=\left(\begin{array}{l}\frac{d \sigma}{d T} \cdot \Delta T_{r} \cdot \delta \\ \frac{d \sigma}{d T} \cdot \Delta T_{z} \cdot \delta\end{array}\right)$

Here $d \sigma / d T=-1.8 \times 10^{-4} \mathrm{~N} /(\mathrm{m} \cdot \mathrm{K})$ is the temperature gradient of surface tension in water [33]. For example, $\delta$ would be 0 in the liquid $\left(V_{f, l}=1\right)$ or vapor $\left(V_{f, v}=1\right)$. Therefore, the Marangoni force would only act on the liquid-vapor interface.

The thermal conductivity and specific heat are computed as functions of the volume fraction of the two phases:

$\kappa=\left(\kappa_{l}-\kappa_{v}\right) V_{f, l}+\kappa_{v}$

$C_{p}=\left(C_{p, l}-C_{p, v}\right) V_{f, l}+C_{p, v}$

The equations governing the interface dynamics of a two-phase flow can be described by the Cahn-Hilliard equation. The equation for the phase field variable is modified to allow for the change of phase

$\frac{\partial \phi}{\partial t}+\mathbf{u} \cdot \nabla \phi-m \delta\left(\frac{V_{f, v}}{\rho_{v}}+\frac{V_{f, l}}{\rho_{l}}\right)=\nabla \cdot \frac{\gamma \lambda}{\varepsilon^{2}} \nabla \Psi$

Here $\gamma$ is the mobility $\left(\mathrm{m}^{3} \cdot \mathrm{s} / \mathrm{kg}\right)$, which is set about $10 \mathrm{~m}^{3} \cdot \mathrm{s} / \mathrm{kg}$. It must be large enough to retain a constant interfacial thickness but small enough so that the convective terms are not overly damped. $\Psi$ is the phase field auxiliary function, which can be represented by the equation.

$\Psi=-\nabla \cdot \varepsilon^{2} \nabla \phi+\left(\phi^{2}-1\right) \phi$

\subsection{Boundary conditions and initial conditions}

In Fig. 1, the boundary conditions about the flow process can be described as follows. Boundary (1) is the axisymmetric boundary.
Table 1

Physical properties of materials.

\begin{tabular}{llll}
\hline Property & Vapor & Water & Description \\
\hline$\rho\left[\mathrm{kg} / \mathrm{m}^{3}\right]$ & $\left(\mathrm{p}+\mathrm{p}_{0}\right) \cdot \mathrm{M}_{\mathrm{w}} / 8.314 / T$ & $1 \times 10^{3}$ & Density \\
$\eta[\mathrm{Pa} \cdot \mathrm{s}]$ & $4 \times 10^{-5}$ & $1 \times 10^{-3}$ & Dynamic viscosity \\
$\kappa[\mathrm{W} /(\mathrm{m} \cdot \mathrm{K})]$ & $8.3154 \times 10^{-5} \cdot T$ & 0.63 & Thermal conductivity \\
& $-7.4556 \times 10^{-3}$ & & \\
$\sigma[\mathrm{N} / \mathrm{m}]$ & 0.0588 & 0.0588 & $\begin{array}{l}\text { Surface tension coefficient } \\
C_{p}[\mathrm{~J} /(\mathrm{kg} \cdot \mathrm{K})]\end{array}$ \\
\hline
\end{tabular}

Table 2

Constant terms in the simulation.

\begin{tabular}{lll}
\hline Expression & Value & Description \\
\hline$M_{w}[\mathrm{~kg} / \mathrm{mol}]$ & 0.018 & Molecular weight of water \\
$\Delta H_{v l}[\mathrm{~J} / \mathrm{mol}]$ & $42,000 / \mathrm{M}_{\mathrm{w}}$ & Latent heat of vaporization \\
$T_{\text {sat }}[\mathrm{K}]$ & 373.15 & Saturate temperature, $1 \mathrm{~atm}$ \\
$C[\mathrm{~m} / \mathrm{s}]$ & 0.03 & Constant term in Eq. $(6)$ \\
$\frac{d \sigma}{d T}[\mathrm{~N} /(\mathrm{m} \cdot \mathrm{K})]$ & $-1.8 \times 10^{-4}$ & Temperature gradient of surface tension \\
\hline
\end{tabular}

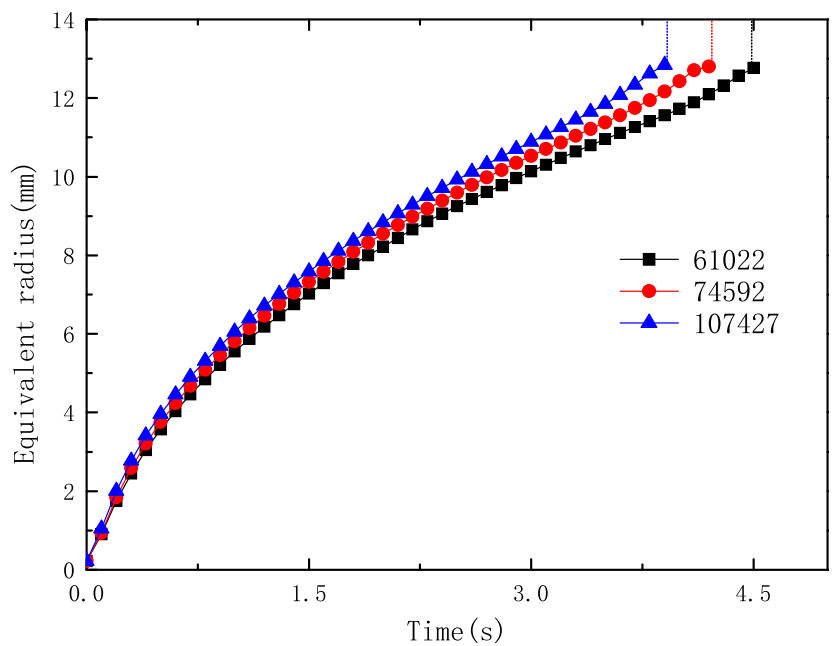

(a)

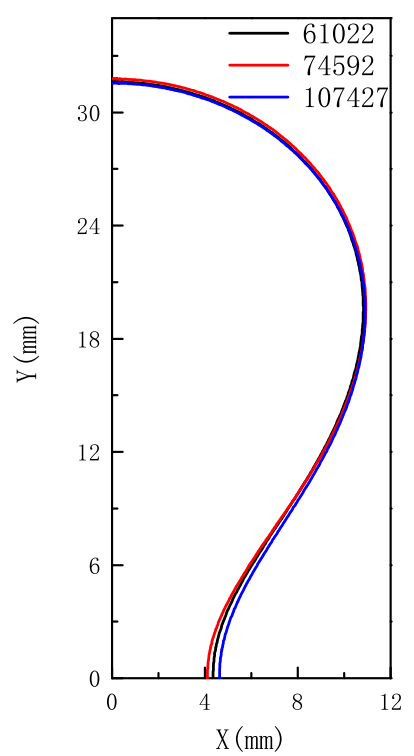

(b)

Fig. 2. Grid independence test at various grid elements for subcooling $=1 \mathrm{~K}$, (a) the bubble growth; (b) the bubble shape at departure 
Boundary (2) is regarded as the no viscous stress outlet boundary. Boundary (3) is the ideal non slip boundary. Boundary (4) could be regarded as the wetted wall. Boundary (5) is the interface of vapor and liquid. As for the boundary conditions about the heat transfer process, boundaries (1), (2) and (3) are the thermal insulation boundaries. Boundary (4) is the heat flux boundary, and the heat transfer coefficient is $5000 \mathrm{~W} /\left(\mathrm{m}^{2} \cdot \mathrm{K}\right)$. Boundary (5) is the heat conduction boundary.

The working fluid used in the present study is water at $101,325 \mathrm{~Pa}$. One can refer to the physical properties of materials in Table 1. And the constant terms in the simulation are shown in Table 2.

\subsection{Grid independence test}

Advancing front triangle meshes are used to discretize the domain, and refine the possible trajectories of the bubbles. In other words, finer meshes would be applied around symmetric axis and boundary where the vapor bubble may occupy. To determine the grid independence of the simulation, Fig. 2 shows the simulation results of different grid quantities. Although the difference of bubble growth periods is slight, the shapes and equivalent radius at departure for the three grids have shown insignificant differences. Thus, numerical simulations are conducted on 61,022 triangular structured grids whose maximum element size is $2 \times 10^{-4} \mathrm{~m}$, minimum element size is $8 \times 10^{-5} \mathrm{~m}$ in the main domain. Moreover, the maximum element size is $1.34 \times 10^{-4} \mathrm{~m}$, and the minimum element size is $4 \times 10^{-7} \mathrm{~m}$ in the boundary (1) as well as the boundary (4) in Fig. 1.

\section{Model verification}

Lee and Merte [34] has conducted boiling experiments using R113 by space flight. A gold film sputtered on a quartz substrate was used as both heater and temperature sensor. In their experiments, steady nucleate boiling could occur when the subcooling increase to $22 \mathrm{~K}$. A large bubble served as a reservoir for a great deal of smaller bubbles growing on the surface, and maintained its size constantly. Later, the same phenomena also appeared in the experiments performed by Kim and Benton [35]. They investigated the highly subcooled pool boiling heat transfer with a microscale heater array at different gravity levels. FC-72 was used as the test fluid and subcooled about $36 \mathrm{~K}$ at $1 \mathrm{~atm}$ for all cases. They found that a large primary bubble formed and moved randomly on the surface in low-g. The primary bubble was surrounded by smaller satellite bubbles which finally merged with it. The primary bubble was formed by the coalescence of smaller bubbles generated on the surface, but maintained its size constantly for a given superheat due to the balance between coalescence with the smaller bubbles at its base and condensation at the top of the bubble.

To verify the phenomena that the bubble remained relatively constant in size at a critical subcooling under the microgravity mentioned in the literatures [34,35], a bubble growing in different

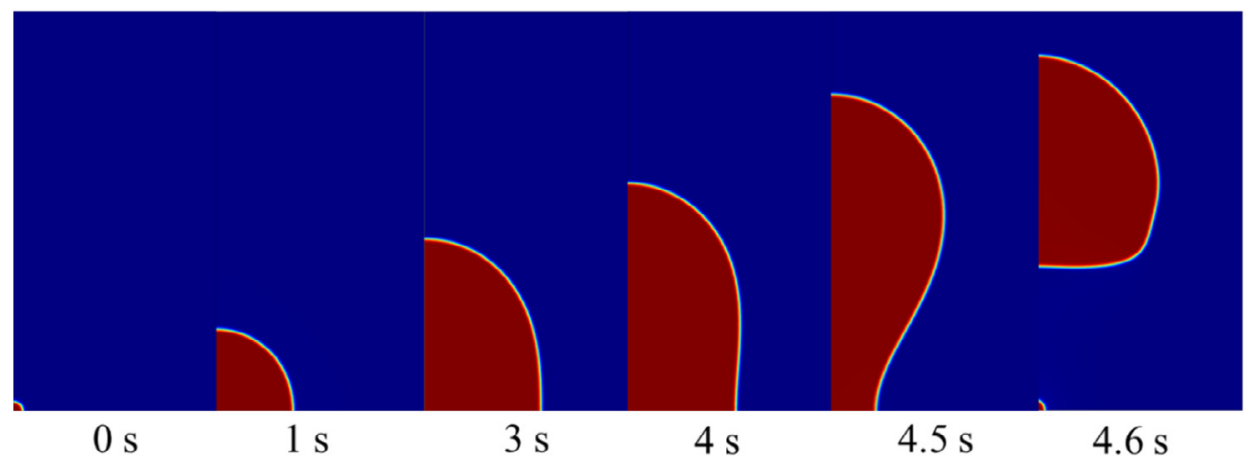

(a)

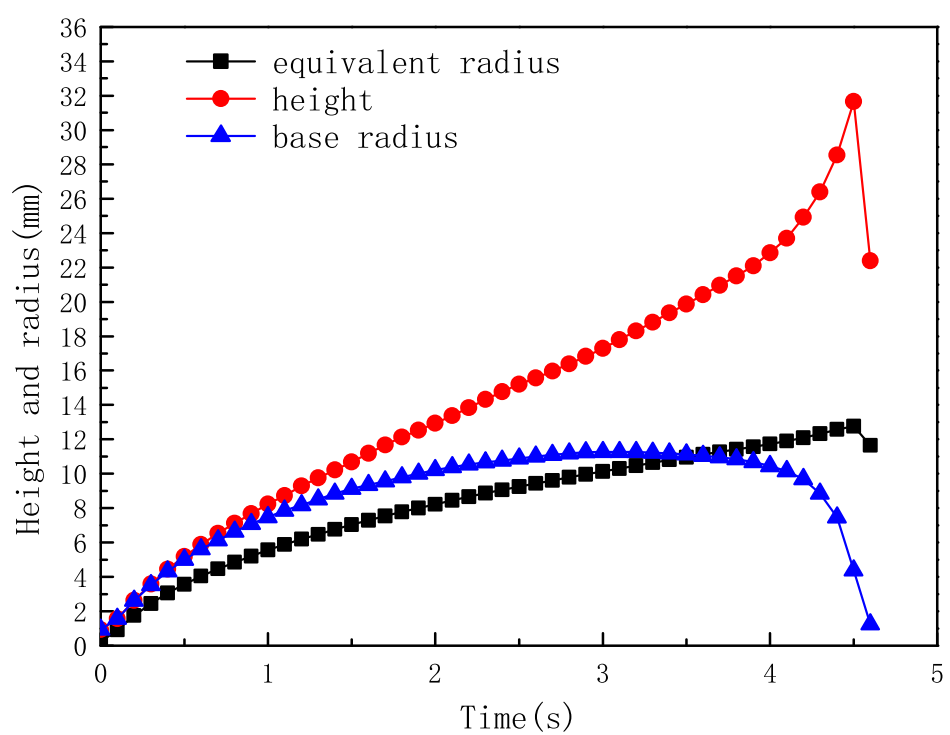

(b)

Fig. 3. (a) Bubble shape and (b) bubble size for subcooling $=1 \mathrm{~K}$ 
subcooling liquid has been simulated. In this section, the conditions are $\Delta T_{w}=5.5 \mathrm{~K}, \theta=90^{\circ}, g_{z} / g_{e}=0.04$. Here $g_{e}$ is the earth normal gravity. Fig. 3 shows the computed growth and departure of single bubble for a liquid subcooling of $1 \mathrm{~K}$. As shown in Fig. 3(a), an initial bubble is placed on the heater surface at $\mathrm{t}=0 \mathrm{~s}$. Then the bubble grows rapidly with the time due to evaporation. Fig. 3(b) shows that the bubble base expands before $3 \mathrm{~s}$ and then shrinks, while the height continuously increases until the bubble departs from the heater surface. The equivalent radius which is calculated assuming a sphere of equal volume also keeps increasing until the departure of the bubble.

However, when the subcooling increases to as high as $8 \mathrm{~K}$, the bubble would not lift off from the surface shown in Fig. 4. The bubble shape would not change after $6 \mathrm{~s}$ from Fig. 4(a). And the equivalent radius remains a constant size of $10.5 \mathrm{~mm}$ while the height and base radius fluctuate around a certain value according to Fig. 4(b). This indicates that a balance between evaporation at the bubble base and condensation on the bubble cap, which is consistent with the literatures [34,35].

Later, the pressure difference analysis is carried out to compare against the solution of Young-Laplace equation. Based on the results of Young-Laplace equation, the error is no more than $15 \%$. For example, when the bubble grows to $1.5 \mathrm{~s}$ in Fig. 5, the pressure difference of two phases at point $\mathrm{A}$ is $14.56 \mathrm{~Pa}$. And the surface tension coefficient at point $A$ is $0.05895 \mathrm{~N} / \mathrm{m}$. The radius of curvature at point $A$ is $8.75 \mathrm{~mm}$. According to the Young-Laplace equation

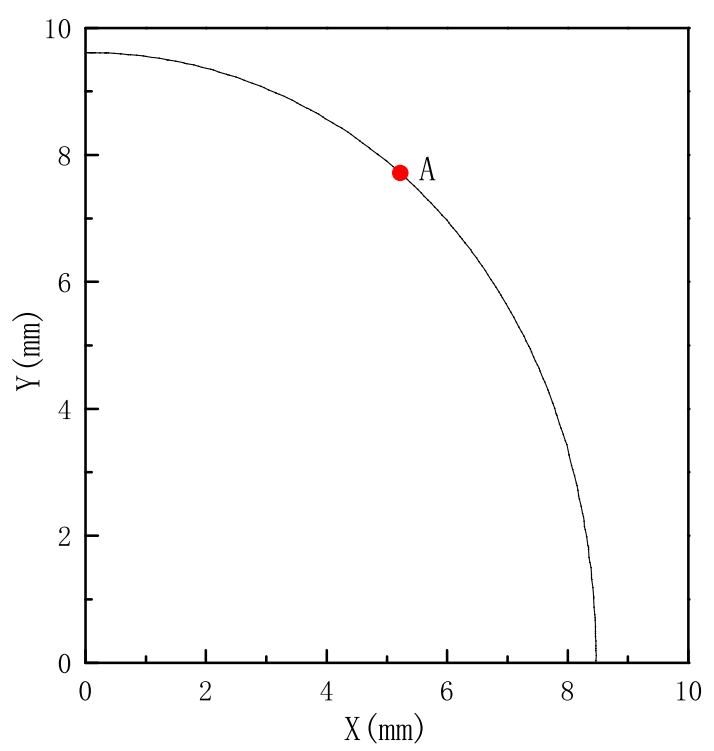

Fig. 5. Bubble shape at $\mathrm{t}=1.5 \mathrm{~s}$ for subcooling $=8 \mathrm{~K}$.

$\Delta p=\frac{2 \sigma}{R}$, the right side of the equation is equal to $13.47 \mathrm{~Pa}$. The error $\frac{14.56-13.47}{14.56} \times 100 \%=7.49 \%$ is less than $15 \%$, which could be acceptable.

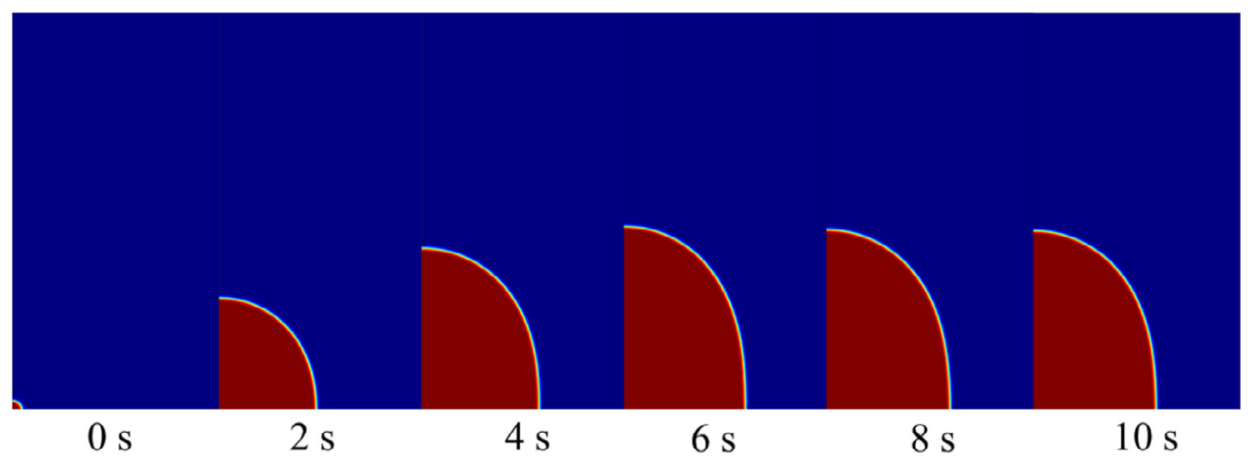

(a)

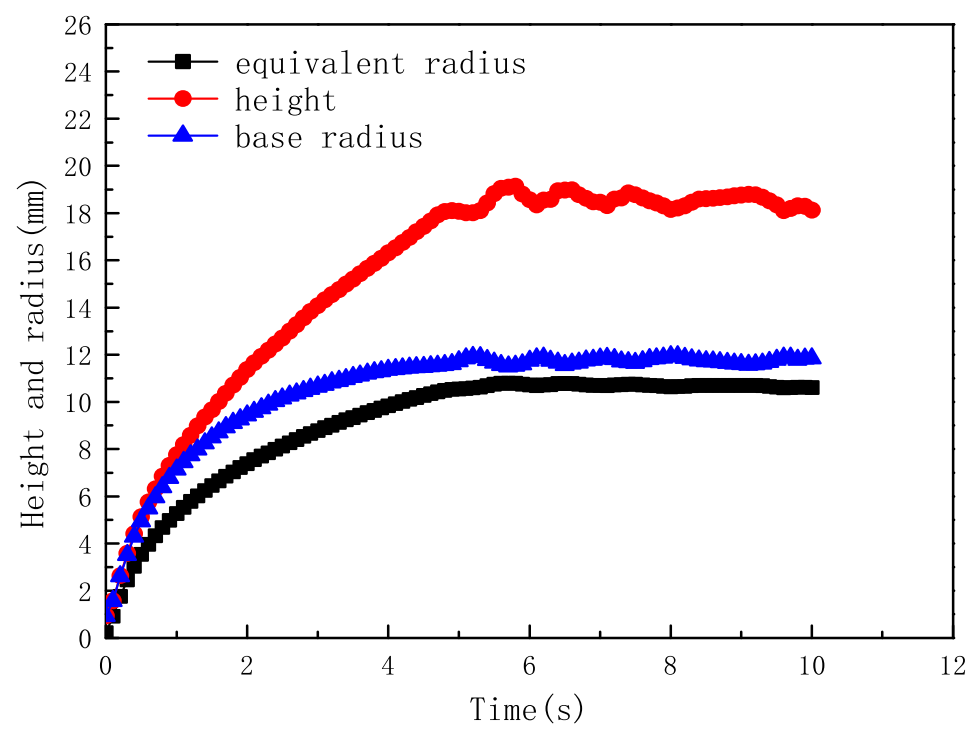

(b)

Fig. 4. (a) Bubble shape and (b) bubble size for subcooling $=8 \mathrm{~K}$. 


\section{Results and discussion}

In this part, the numerical results about the effects of gravity, contact angle and wall superheat on the critical subcooling are presented. The characteristics of heat transfer with a constant size bubble on the surface will be discussed at last. All the numerical results correspond to the computations of bubble growth for the first cycle.

\subsection{Effect of gravity}

Fig. 6 illustrates the effects of gravity on the growth size and growth period at $\Delta T_{w}=5.5 \mathrm{~K}, \theta=90^{\circ}, \Delta T_{\text {sub }}=1 \mathrm{~K}$. It can be seen that the effect of gravity level on the growth period when the bubble lifts off is notable. When the gravity level increases from $0.04 \mathrm{~g}_{\mathrm{e}}$ to $0.12 \mathrm{~g}_{\mathrm{e}}$, the growth period reduces from $4.6 \mathrm{~s}$ to $1.6 \mathrm{~s}$. In addition, it's obvious that the bubble lifting off the surface at the same subcooling has a smaller departure radius with a larger gravity.

In Fig. 7, the solid line shows the equivalent departure radius with the variable subcooling under different gravity, while the dashed line represents the max equivalent radius where the bubble adheres to the surface. As shown in Fig. 7, the equivalent departure radius changes little with subcooling below the critical subcooling,

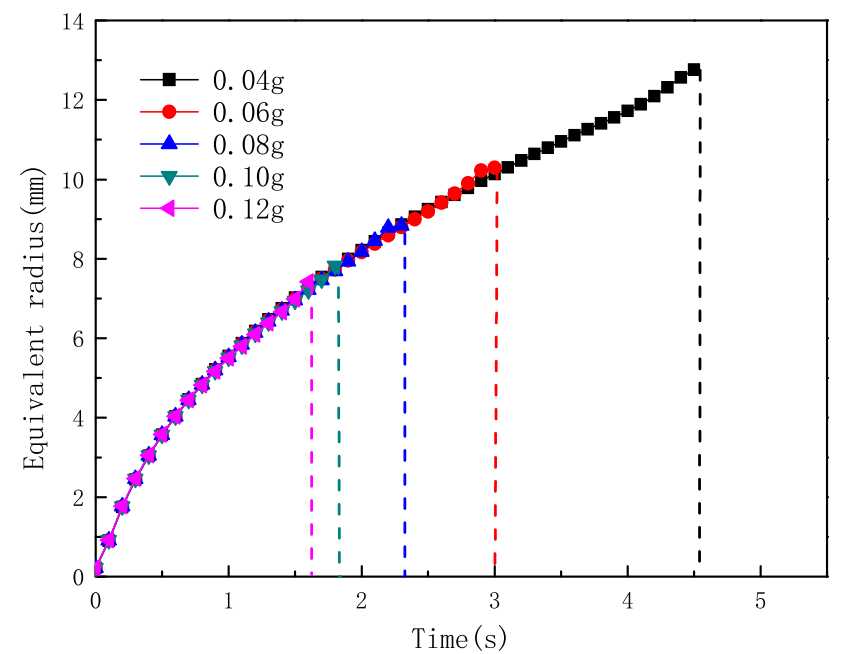

(a)

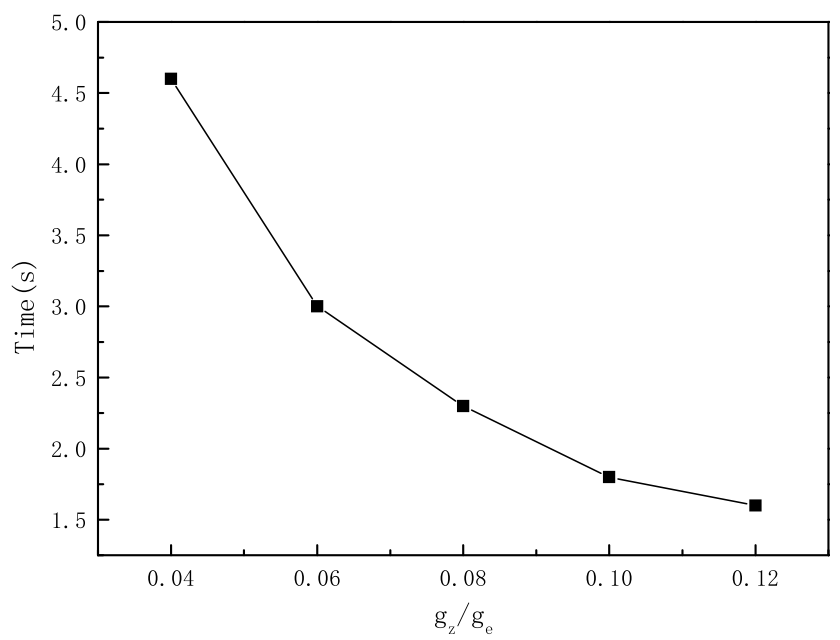

(b) while the max equivalent radius decreases with increasing subcooling above the critical subcooling. It is because that whether the bubble grows or not is controlled by evaporation and condensation, while whether the bubble lifts off or not is controlled by the total force. Especially, when the bubble equivalent radius with low subcooling exceeds the critical radius under low gravity, the bubble would depart. However, if the bubble equivalent radius whose condensation goes beyond evaporation with high subcooling at later stages is less than the critical radius, the bubble would adhere to the surface and get condensed until it disappears.

Fig. 8 shows the critical subcooling as a function of gravity level. As is illustrated in Fig. 8, the larger gravity level is, the greater the critical subcooling is. This is explained that the bubble has a lesser departure radius and could easily depart from the surface with relatively large buoyancy at a high gravity level. Therefore, in order to keep the bubble on the surface, the critical subcooling involved with the condensation rate should increase with the increase of gravity level.

\subsection{Effect of contact angle}

The dependence of bubble growth on surface wettability is calculated when the contact angles are $50^{\circ}, 60^{\circ}, 70^{\circ}, 80^{\circ}, 90^{\circ}$ and $100^{\circ}$

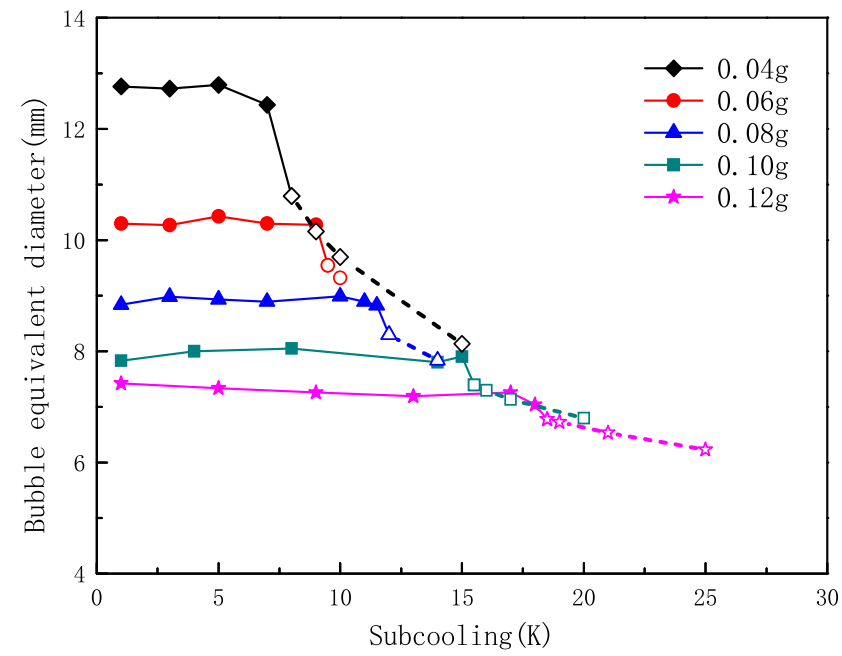

Fig. 7. Bubble equivalent radius as a function of subcooling under different gravity level.

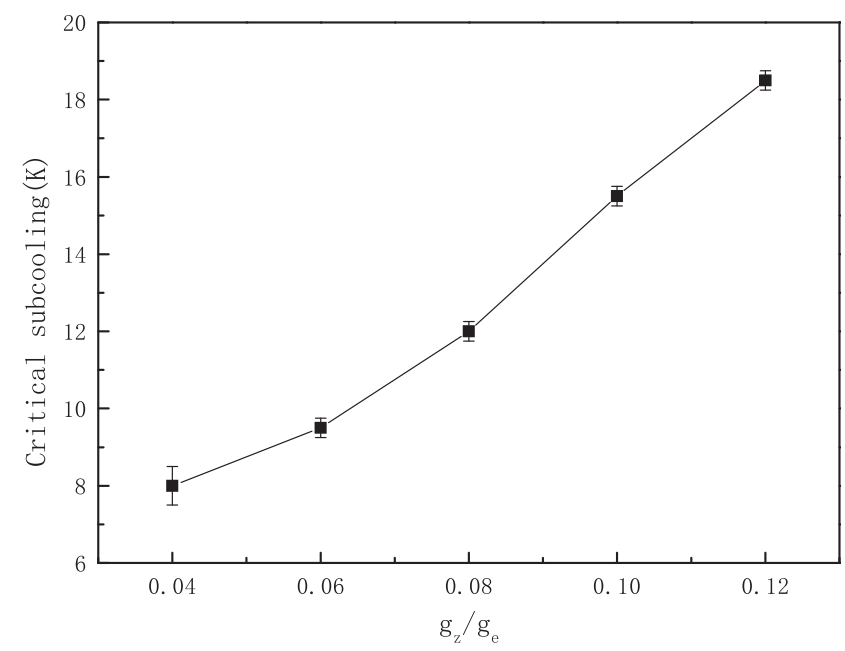

Fig. 8. The critical subcooling as a function of gravity level.

Fig. 6. (a) Growth size and (b) growth period for subcooling $=1 \mathrm{~K}$. 


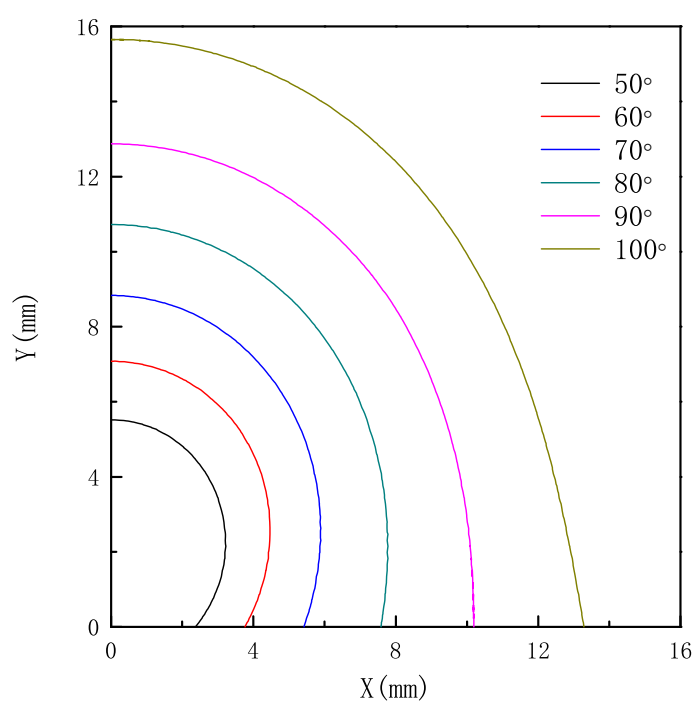

(a)

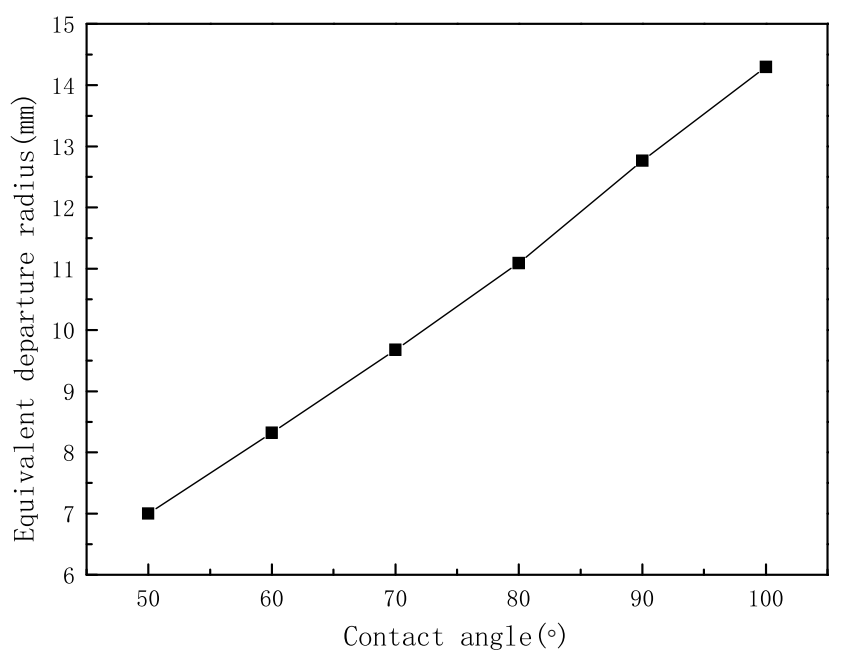

(b)

Fig. 9. (a) Bubble shape and (b) departure radius as a function of contact angle.

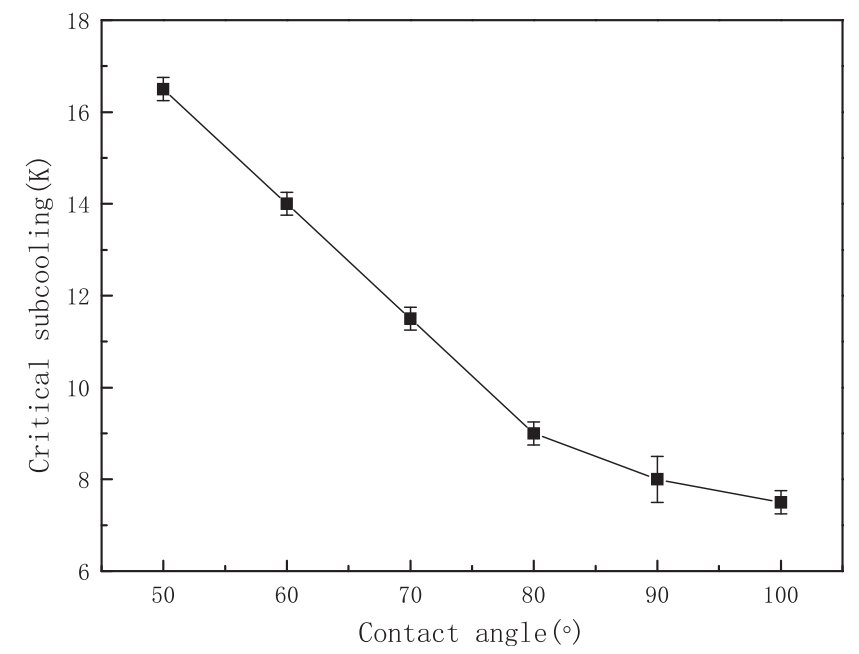

Fig. 10. The relationship between critical subcooling and contact angle.

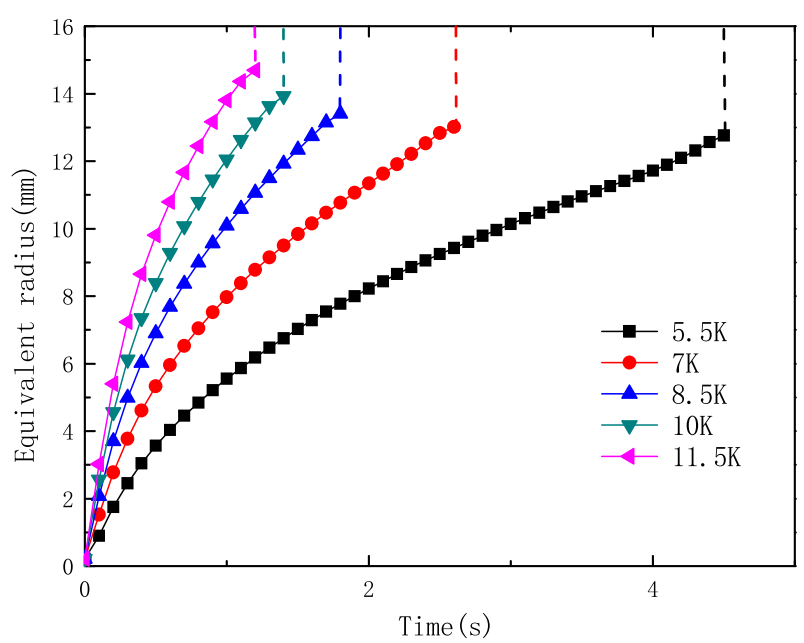

(a)

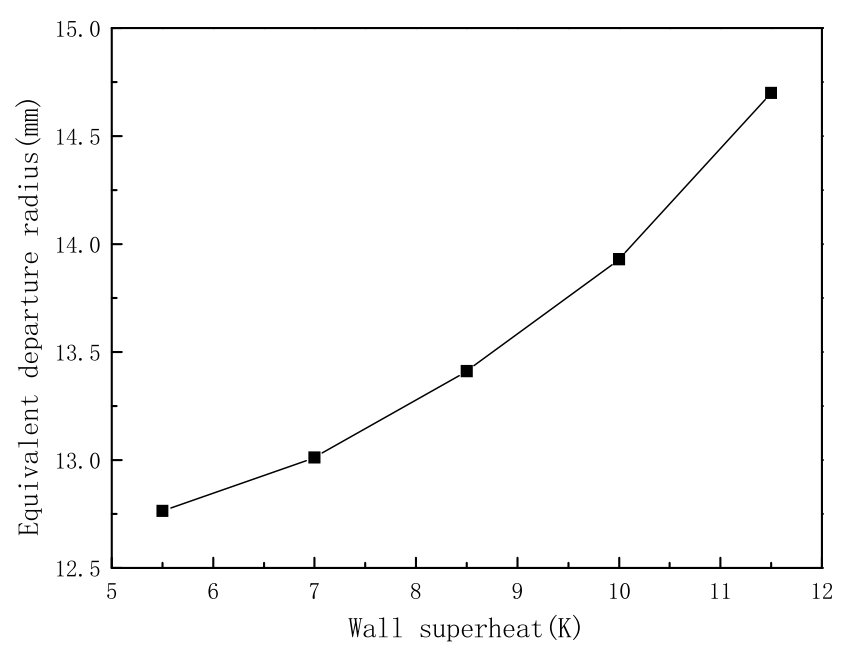

(b)

Fig. 11. (a) Growth size and (b) departure radius under different wall superheat.

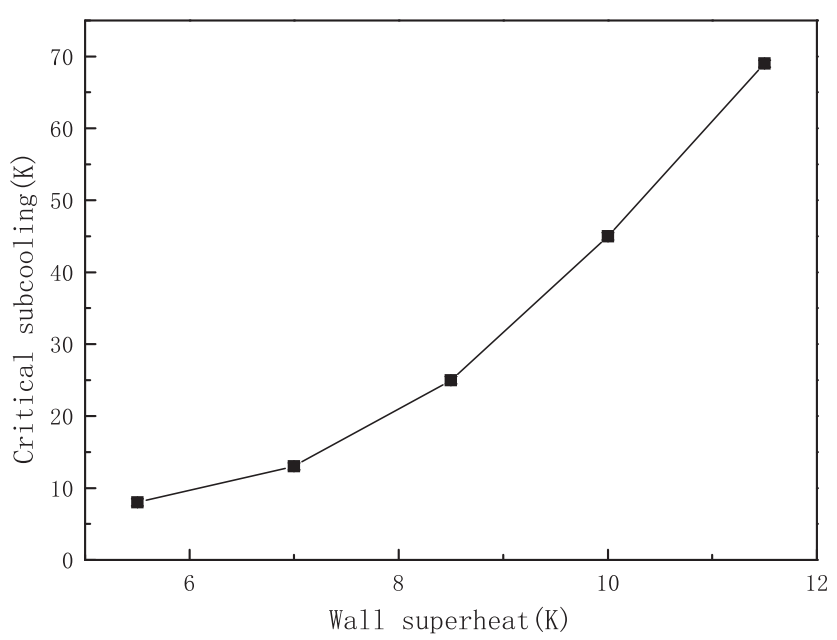

Fig. 12. The critical subcooling as a function of wall superheat. 
under the conditions of $g_{z} / g_{e}=0.04, \Delta T_{w}=5.5 \mathrm{~K}$. Fig. 9(a) shows the shapes of the bubble at $\mathrm{t}=2.0 \mathrm{~s}$ for liquid subcooling about $1 \mathrm{~K}$. As the contact angle increases, the bubble height and base radius enlarge. As shown in Fig. 9(b), the trend of equivalent departure radius is given with the contact angle changing. It's clear that the bubble has a relatively departure radius with a large contact angle, which could be caused by the surface tension dragging the bubble to the surface. According to Son et al. [21], a larger contact angle results in the bigger force pointing to the surface. Therefore, the bubble would grow bigger to detach from the surface. Especially, when the contact angle is large enough, the heating surface might be covered by a vapor film, resulting in the dry-burning on the heating surface.

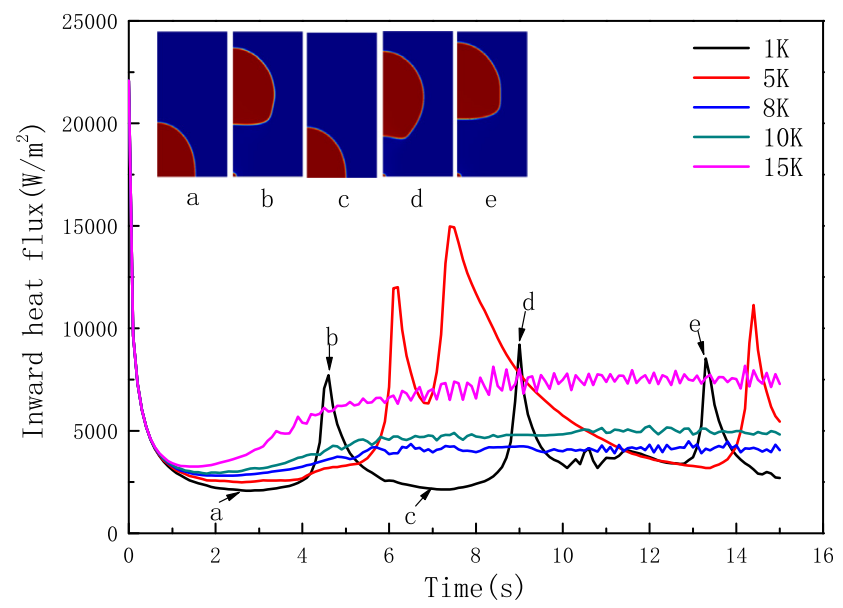

Fig. 13. The inward heat flux for the departing bubble and non-departing bubble.
The critical subcooling values under different contact angle are displayed in Fig. 10. As a result the critical subcooling decreases from $16.5 \mathrm{~K}$ to $7.5 \mathrm{~K}$ when the contact angle increases from $50^{\circ}$ to $100^{\circ}$. As mentioned above, the bubble has a smaller departure radius and could easily depart from the surface with relatively little surface tension at a small contact angle. To keep the bubble with a constant size on the surface, the critical subcooling referred to condensation rate should increase when the contact angle decreases.

\subsection{Effect of wall superheat}

Fig. 11 shows the bubble growth size and departure radius in different wall superheats when the subcooling, contact angle, gravity level remain unchanged $\left(\Delta T_{\text {sub }}=1 \mathrm{~K}, \theta=90^{\circ}, g_{z} / g_{e}=0.04\right)$. It can be seen that the vapor production rates increase with increasing wall superheat in Fig. 11(a). Therefore, the growth period decreases from $4.6 \mathrm{~s}$ to $1.2 \mathrm{~s}$ when $\Delta T_{w}$ is increases from $5.5 \mathrm{~K}$ to $11.5 \mathrm{~K}$. Meanwhile, the bubble radius at departure increases with wall superheat in Fig. 11(b).

Fig. 12 gives the tendency of the critical subcooling with the wall superheat. It can be seen from the figure that in order to drag the bubble on the surface, the critical subcooling increases with wall superheat at the same contact angle and gravity level. This is due to that higher wall superheat leads to greater evaporation, which needs greater condensation to keep the bubble with a constant size on the surface correspondingly, thus resulting in higher critical subcooling.

\subsection{Analyses of heat transfer}

As has been noted, the critical subcooling is $8 \mathrm{~K}$ under the conditions of $g_{z} / g_{e}=0.04, \theta=90^{\circ}, \Delta T_{w}=5.5 \mathrm{~K}$. Therefore, the bubble would lift off with the subcooling about $1 \mathrm{~K}$ and $5 \mathrm{~K}$, while the

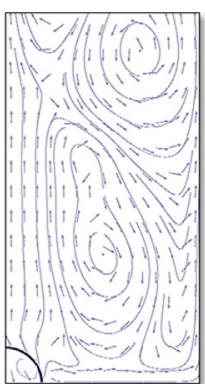

$4.9 \mathrm{~s}$

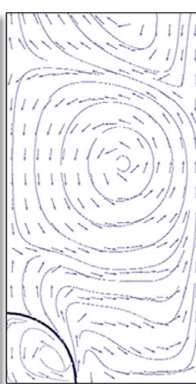

$5.5 \mathrm{~s}$

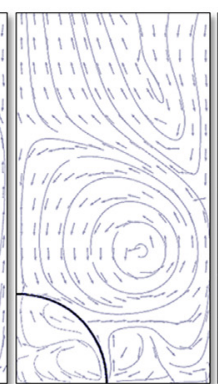

$6.0 \mathrm{~s}$

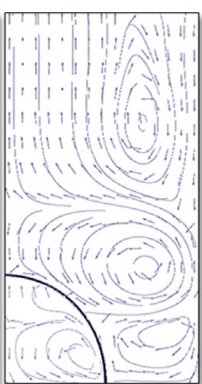

$6.5 \mathrm{~s}$

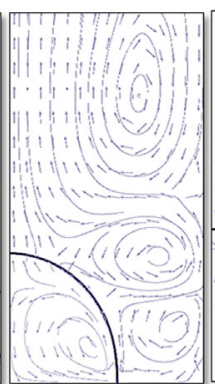

$7.0 \mathrm{~s}$

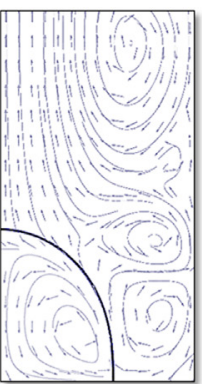

$7.5 \mathrm{~s}$

(a)

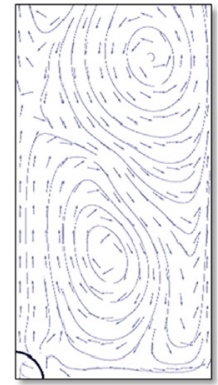

$6.5 \mathrm{~s}$

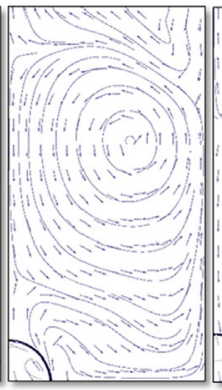

$6.8 \mathrm{~s}$

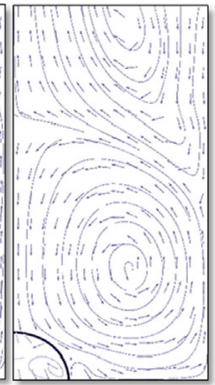

$7.1 \mathrm{~s}$

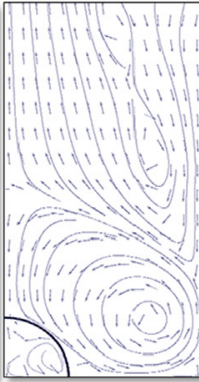

$7.4 \mathrm{~s}$

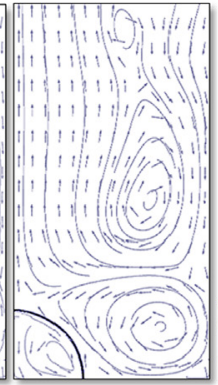

$7.7 \mathrm{~s}$

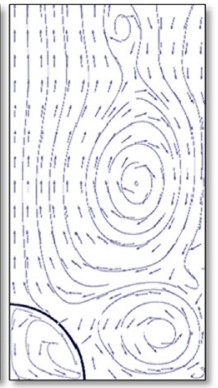

$8.0 \mathrm{~s}$

(b)

Fig. 14. Flow field after the bubble departure under the condition of (a) subcooling $=1 \mathrm{~K}$ and (b) subcooling $=5 \mathrm{~K}$. 
bubble would adhere to the surface with the subcooling about $8 \mathrm{~K}$, $10 \mathrm{~K}$ and $15 \mathrm{~K}$. Fig. 13 displays the inward heat flux for the departing bubble and non-departing bubble. In the beginning, the inward heat flux drops down under all subcooling. This is caused by expansion of bubble base with evaporation, which lowers the contact area between the liquid and the heater surface, reducing the efficiency of heat transfer. Then, the departing bubble and nondeparting bubble show different heat transfer characteristics. Due to the contraction of bubble base, the liquid rewets the area occupied by the vapor before. Therefore, the inward heat flux of the departing bubble increases with time. Besides, the heat flux changes periodically with bubble growth and departure.

As for the peak that occurs after bubble departure with the subcooling about $5 \mathrm{~K}$, it attributes to strong convection heat transfer caused by the wake flow after the bubble lifts off the surface. Fig. 14 shows the flow field after the bubble departure with the subcooling about $1 \mathrm{~K}$ and $5 \mathrm{~K}$. The curves and arrows represent the streamlines and the directions of the flow respectively. It's clear that an anticlockwise vortex moves from the upper boundary to the lower boundary after the bubble departure, taking the colder liquid in the upper part of the domain to the heated wall. However, Fig. 14(a) and (b) shows some other different features. In Fig. 14(a) the vortex could not reach the heated wall since the bubble grows fast. Nevertheless, the vortex would reach the heated wall owing to a smaller bubble in Fig. 14(b), which would strengthen the heat transfer. Hence, a peak occurs after the bubble departure with subcooling about $5 \mathrm{~K}$. The heat flux of the non-departing bubble rises a little due to the enhancement of heat conduction as subcooling increases. The reason why the heat flux fluctuates at a certain value is explained that a slight shape oscillation occurs due to hydrodynamic instability shown in Fig. 15. And owing to the bubble adhering to the surface, the heat flux is small without rewetting.

Fig. 16 shows the average heat flux as a function of subcooling. The average heat flux increases with subcooling under the departing conditions. And the same tendency goes for the non-departing conditions. While there is a sharp drop in average heat flux when it transforms from the departing condition to the non-departing condition with increasing subcooling. The reason why the average heat flux increases with subcooling under both departing and nondeparting conditions is that the heat conduction on the surface gets enhanced with as subcooling increases. As for the drop occurred in transformation, it's due to bubble departing that causes

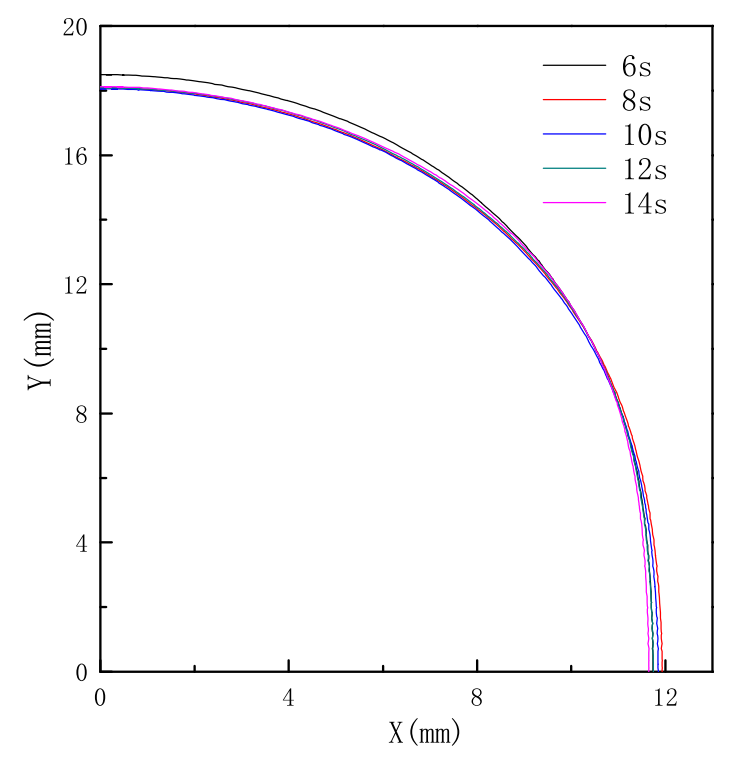

Fig. 15. Shape oscillation with the subcooling $=8 \mathrm{~K}$.

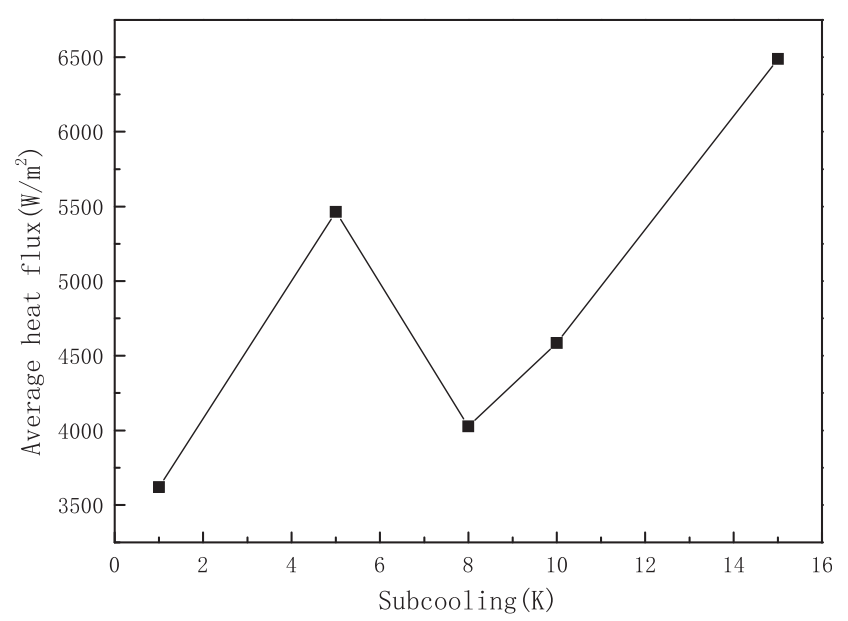

Fig. 16. The average heat flux as a function of subcooling.

rewetting on the surface and wake flow. Therefore, the average heat flux at subcooling about $5 \mathrm{~K}$ is larger than that at subcooling about $8 \mathrm{~K}$. Although the average heat flux is large at high subcooling about $15 \mathrm{~K}$ shown in Fig. 16, it would turn into the single phase flow whose heat transfer efficiency is far lower than the multiphase flow when the bubble vanishes in high subcooling.

\section{Conclusions}

In the present paper, the numerical simulation of a single vapor bubble growth in subcooling liquid has been carried out by the phase field method. A thin superheated layer and thermocapillary convection effect are considered. The effects of gravity level, contact angle and wall superheat on the bubble growth, critical subcooling, together with heat transfer have been investigated. The simulation results show that:

(1) The bubble behavior in the numerical model agrees well with previous experiments in high subcooling liquid under microgravity. With the increase in subcooling, the bubble would maintain its size constantly at a critical subcooling, transforming from departing conditions to non-departing conditions. It is easy to find that the superheated layer is of great importance to predict bubble behavior. For simplicity, microlayer evaporation underneath the growing bubble is neglected in the model, which might be essential to the heat transfer mechanism. For further study, microlayer modeling will be incorporated with the built model to obtain more reliable data.

(2) The gravity level has a great impact on bubble growth and the critical subcooling. The growth period and departure radius show the same tendency. Both of them reduce with the increase in gravity level. Comparatively, the critical subcooling increases slightly. Large contact angle at the threephase contact line augments the departure radius. However, the critical subcooling decreases as contact angle increases. The effect of wall superheat on bubble growth and the critical subcooling is significant. As the wall superheat increases, the growth period reduces rapidly, while the departure radius and the critical subcooling increase.

(3) As indicated in the paper, the departing bubble is a highly efficient way of heat transfer which is involved with rewetting process and wake flow. In contrast, the non-departing bubble adhering to the surface would prevent heat transfer with a dry spot, which may damage the heating element in application. 


\section{Conflict of interest}

The authors declared that there is no conflict of interest.

\section{Acknowledgements}

This work is financially supported by the National Natural Science Foundation of China (Grant No. 51274137, U1860107 and U1738105).

\section{References}

[1] H.C. Lee, B.D. Oh, S.W. Bae, M.H. Kim, Single bubble growth in saturated pool boiling on a constant wall temperature surface, Int. J. Multiph. Flow 29 (12) (2003) 1857-1874.

[2] J. Kim, Review of nucleate pool boiling bubble heat transfer mechanisms, Int. J. Multiph. Flow 35 (12) (2009) 1067-1076.

[3] W. Lee, G. Son, Numerical simulation of boiling enhancement on a microstructured surface, Int. Commun. Heat Mass Transfer 38 (2) (2011) $168-173$.

[4] W. Lee, G. Son, H.Y. Yoon, Numerical study of bubble growth and boiling heat transfer on a microfinned surface, Int. Commun. Heat Mass Transf. 39 (1) (2012) 52-57.

[5] V.K. Dhir, G.R. Warrier, E. Aktinol, Numerical simulation of pool boiling: a review, J. Heat Transf. - Trans. ASME 135 (2013) (6).

[6] S. Jung, H. Kim, An experimental method to simultaneously measure the dynamics and heat transfer associated with a single bubble during nucleate boiling on a horizontal surface, Int. J. Heat Mass Transf. 73 (2014) 365-375.

[7] C.Y. Zhang, P. Cheng, J.G. Cao, Mesoscale simulation of Marangoni convection about a vapor bubble in a liquid with temperature gradients under microgravity conditions, Int. Commun. Heat Mass Transf. 78 (2016) 295-303.

[8] S. Gong, P. Cheng, Direct numerical simulations of pool boiling curves including heater's thermal responses and the effect of vapor phase's thermal conductivity, Int. Commun. Heat Mass Transf. 87 (2017) 61-71.

[9] C.R. Kharangate, I. Mudawar, Review of computational studies on boiling and condensation, Int. J. Heat Mass Transf. 108 (2017) 1164-1196.

[10] R. Siegel, Effects of reduced gravity on heat transfer, Adv. Heat Transf. 4 (1967) $143-228$.

[11] J. Kim, J. Mcquillen, Subcooled pool boiling in variable gravity environments, J. Heat Transf. 131 (9) (2009) 258-262.

[12] D.M. Qiuand, V.K. Dhir, D. Chao, M.M. Hasan, E. Neumann, G. Yee, A. Birchenough, Single-bubble dynamics during pool boiling under low gravity conditions, J. Thermophys. Heat Transf. 16 (3) (2002) 336-345.

[13] H. Merte, Some parameter boundaries governing microgravity pool boiling modes, Ann. N. Y. Acad. Sci. 1077 (1) (2006) 629-649.

[14] J.F. Zhao, J. Li, N. Yan, S.F. Wang, Bubble behavior and heat transfer in quasisteady pool boiling in microgravity, Microgravity Sci. Technol. 21 (1) (2009) 175-183.

[15] R. Raj, J. Kim, J. Mcquillen, Pool boiling heat transfer on the International Space Station: experimental results and model verification, J. Heat Transf. 134 (10) (2012) 101504.
[16] V.K. Dhir, E. Aktinol, D. Chao, J. Eggers, W. Sheredy, W. Booth, Nucleate Pool Boiling Experiments (NPBX) on the international space station, Microgravity Sci. Technol. 24 (5) (2012) 307-325.

[17] G.R. Warrier, V.K. Dhir, D.F. Chao, Nucleate Pool Boiling eXperiment (NPBX) in microgravity: international space station, Int. J. Heat Mass Transf. 83 (2015) 781-798.

[18] R. Lee, J. Nydahl, Numerical calculation of bubble growth in nucleate boiling from inception through departure, J. Heat Transf. 111 (2) (1989) 474-479.

[19] P. Stephan, J. Hammer, A new model for nucleate boiling heat transfer, Heat Mass Transf. 30 (2) (1994) 119-125.

[20] S.W.J. Welch, Direct simulation of vapor bubble growth, Int. J. Heat Mass Transf. 41 (12) (1998) 1655-1666.

[21] G. Son, Dynamics and heat transfer associated with a single bubble during nucleate boiling on a horizontal surface, J. Heat Transf. 121 (3) (1999) 623631.

[22] J.F. Zhao, Z.D. Li, L. Zhang, Numerical simulation of single bubble pool boiling in different gravity conditions, in: NEW TRENDS IN FLUID MECHANICS RESEARCH/Proc. 6th Int. Conf. Fluid Mech., June 30-July 3, 2011, Guangzhou, China. AIP Conf., vol. 1376, pp. 565-568.

[23] L. Zhang, Z.D. Li, K. Li, H.X. Li, J.F. Zhao, Influence of heater thermal capacity on bubble dynamics and heat transfer in nucleate pool boiling, Appl. Therm. Eng. 88 (2015) 118-126.

[24] Z.D. Li, L. Zhang, J.F. Zhao, H.X. Li, K. Li, K. Wu, Numerical simulation of bubble dynamics and heat transfer with transient thermal response of solid wall during pool boiling of FC-72, Int. J. Heat Mass Transf. 84 (2015) 409-418.

[25] S. Singh, V. Dhir, Effect of gravity, wall superheat and liquid subcooling on bubble dynamics during nucleate boiling, Microgravity Fluid Phys. Heat Transf. (2000) 106-113.

[26] J. Wu, V.K. Dhir, Numerical simulation of dynamics and heat transfer associated with a single bubble in subcooled boiling and in the presence of noncondensables, J. Heat Transf. 133 (4) (2011) 041502.

[27] L.M. Pan, Z.W. Tan, D.Q. Chen, L.C. Xue, Numerical investigation of vapor bubble condensation characteristics of subcooled flow boiling in vertica rectangular channel, Nucl. Eng. Des. 248 (1) (2012) 126-136.

[28] L. Rayleigh, On the pressure developed in a liquid during the collapse of a spherical cavity, Phil. Mag. 34 (1917) 94-98.

[29] Y. Utaka, Y. Kashiwabara, M. Ozaki, Z. Chen, Heat transfer characteristics based on microlayer structure in nucleate pool boiling for water and ethanol, Int. J. Heat Mass Transf. 68 (2014) 479-488.

[30] K. Yamagata, F. Hirano, K. Nishikawa, H. Matsuoka, Nucleate boiling of water on the horizontal heating surface, Mem. Fac. Eng. Kyushu. 15 (1955) 98.

[31] D. Jacqmin, Calculation of two-phase navier-stokes flows using phase-field modeling, J. Comput. Phys. 155 (1) (1999) 96-127.

[32] S. Shin, S.I. Abdel-Khalik, D. Juric, Direct three-dimensional numerica simulation of nucleate boiling using the level contour reconstruction method, Int. J. Multiph. Flow 31 (10-11) (2005) 1231-1242.

[33] S.Q. Gao, Capillary Mechanics, Science Press, Beijing, 2010.

[34] H.S. Lee, H. Merte, Pool boiling phenomena in microgravity, in: Proceedings of the 11th Int. Heat Transfer Conf., 1998, Kyongju, Korea, vol. 2, pp. 395-400.

[35] J. Kim, J.F. Benton, Highly subcooled pool boiling heat transfer at various gravity levels, Int. J. Heat Fluid Flow 23 (4) (2002) 497-508. 